\title{
RADIOFREQUENCY LUMBAR ZYGAPOPHYSIAL (FACET) JOINT DENERVATION: A Preliminary Report of a New Concept
}

\begin{abstract}
Robert E. Windsor, MD
This is a preliminary report of a new concept of lumbar medial branch neurotomy by measurement of minimal sensory threshold. This technique is not recommended for routine clinical use until further controlled data are available.

The lumbar zygapophysial joints (Z-joint) or facet joints, are a potential source of low back pain. In general, the principle innervation of the Z-joint is the medial branch of the posterior primary ramus of the same level as the target Z-joint as well as the level above.

Denervation of the multifidus as evaluated by electromyography has become a measurement of successful Z-joint denervation. Two drawbacks to this method are that it takes one to several weeks

for denervation potentials to develop and thus does not give the physician any sense of successful denervation intra-operatively. The other is that the Z-joint is innervated by the sensory fibers of the medial branches. As a result, the multifidus may be successfully denervated as demonstrated by electromyography but the Z-joints may be inadequately denervated. As a result, this technique describes measurement of minimal sensory threshold prior to lesioning and seeking to double that threshold as an additional, intra-operative measure of successful sensory denervation of the Z-joint.

Keywords: Facet joint, zygapophysial joint, radiofrequency low back pain, chronic pain
\end{abstract}

The lumbar zygapophysial joints (Zjoint) or facet joints are a potent source of low back pain. Studies in healthy volunteers have shown that stimulating these joints or their sensory nerves may produce low back and/or lower extremity pain (1-4). Indahl et al (5) suggested that the Z-joint may have a regulatory function on the intricate neuromuscular balance. Anesthetizing these joints or their sensory nerves relieves pain in the lower back as well as the pattern of referral (4, 6-13). Despite some investigators' doubts that Z-joint pain exists $(14,15)$, it has now been firmly established through studies using controlled injections to limit falsepositive responses that the prevalence of chronic Z-joint pain in low back pain is between $15 \%$ and $40 \%(8-13,9,16)$.

Despite substantial investigation, no clinical features including history, physical examination, or imaging studies are able to definitively confirm or deny the condition $(8,12,13,17-20)$. Diagnostic blocks are the current mainstay for diagnosis (13).

The lumbar Z-joint can be anesthetized by direct intra-articular injec-

From Georgia Pain Physicians, Marietta, GA and Department of Physical Medicine and Rehabilitation Emory University, Atlanta, GA. Address correspondence: Robert E. Windsor, MD, Georgia Pain Physicians, 2550 Windy Hill Road, Suite 215, Marietta, GA 30067. E-mail: rwindsor@aol.com Funding: No financial support was obtained for this study. tions of local anesthetic or by anesthetizing the neural elements supplying sensation to the joint (6-13). Although there is some dispute (21-29), most authorities agree that the medial branch of the posterior primary ramus arising from the spinal nerve exiting adjacent to the target $\mathrm{Z}$ joint and the descending branch of the medial branch arising from the posterior primary ramus one level above the target Z-joint have been amply demonstrated to innervate the L1-2 through L4-5 Z-joints. The only exception in the lumbar spine is that the L5-S1 Z-joint is innervated by the L4 medial branch and the L5 dorsal ramus (29-32).

Since the medial branch supplies the multifidus muscle with motor innervation as well as sensation to the Z-joints, three studies have utilized electromyography (EMG) to evaluate the effectiveness of radiofrequency (RF) Z-joint neurotomy (33-35). Oudenhoven (33) utilized post-neurotomy EMG only to determine the efficacy of the medial branch neurotomy. Further, he concluded that relief from RF lumbar Z-joint neurotomy was strongly correlated only when signs of bilateral lumbar paraspinal denervation were present on EMG. Dreyfuss et al (34) utilized both a pre-neurotomy EMG to confirm that no denervation predated the procedure and post-neurotomy EMG to evaluate the efficacy of multifidus denervation assuming that this correlated with adequate Z-joint neurotomy. They found a correlation factor between pain relief and EMG demonstrated denervation of 0.61. Finally, Barendse et al (35) found no correlation between post-neurotomy EMG and pain relief following Zjoint neurotomy. As a result of the above discussion it may be seen that there is no agreement on how or if EMG should be used in evaluating the success or failure of lumbar Z-joint neurotomy.

One reason EMG may be only a weak indicator of a successful lumbar Z-joint sensory neurotomy is that the EMG only evaluates the physiologic status of the motor branches and indicates nothing about the status of the sensory fibers. Thus, a positive EMG following a lumbar Z-joint neurotomy may present some pitfalls to the unwitting physician. Since the main intent of RF Z-joint neurotomy is to ablate the sensory fibers of the lumbar medial branch thus anesthetizing the target $\mathrm{Z}$ joint, a partial lesion of the lumbar medial branch could theoretically preferentially damage the motor fibers of the medial branch resulting in a positive post-procedure EMG and leave the sensory fibers intact and functioning. This could happen as a result of a partial lesion of the mixed nerve proximal to the division of the sensory or motor branches from the main trunk or a partial or complete lesion of the medial branch after the sensory branches have already divided from the main trunk (Fig 1). Assuming the patient's pain remains post-neurotomy and if the physi- 


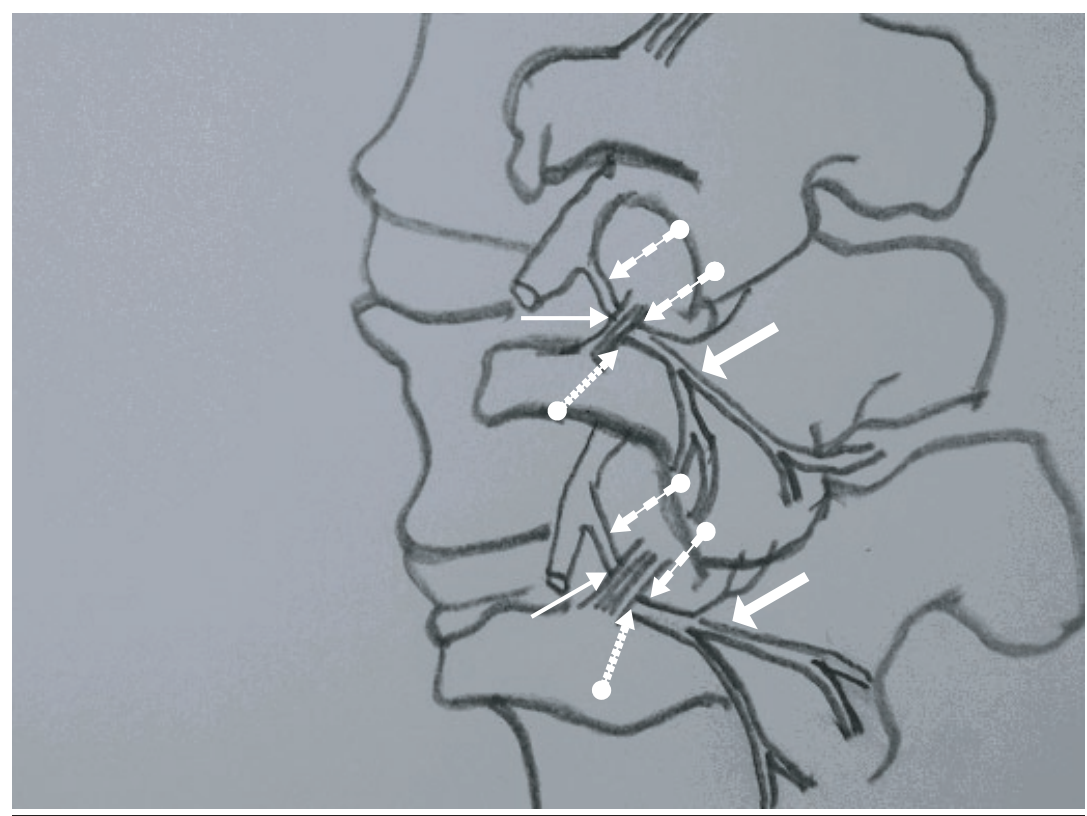

Figure 1. Sketch of the relevant neuroanatomy of the lumbar zygapophyseal joint. Mammiloaccessory ligament (Thin continuous arrow), Long hashed arrow (trunk of medial branch, mixed nerve), Short hashed arrow (Theoretical site for a partial lesion producing abnormal multifidus EMG with suboptimal Z-joint neurotomy), Bold continuous arrow (Theoretical site for a partial or complete lesion producing abnormal multifidus EMG with suboptimal Z-joint neurotomy.

cian assumes that the Z-joint had been adequately anesthetized by the neurotomy due to a positive post-neurotomy multifidus EMG, then the physician may abandon the Z-joint as a potential source of pain and move on to other more invasive procedures including surgery.

In addition to discussion regarding the need for post-procedure EMG, there is disagreement on other elements of the technique. During routine lumbar Zjoint RF neurotomy, it is standard to perform an investigative electrical stimulation prior to a RF lesion. Once the probe is optimally placed from a radiographic standpoint the medial branch is stimulated. Some authors advocate this stimulation to confirm that the exposed tip of the RF probe is not too near the spinal nerve, dorsal root ganglion, or anterior ramus at 2-5 Hz or $50-100 \mathrm{~Hz}$ (28-38). Others recommend its usage as a means of confirming that the probe is lying adjacent to the medial branch by visualizing and/or palpating a multifidus muscle twitch at $2-5$ $\mathrm{Hz}$ (39). In essence, most investigators feel that a pre-lesion electrical stimulation is important, but there is some disagreement on how it should be used. Upon electrical stimulation, if there is no radicular paresthesia at $50-100 \mathrm{~Hz}$ and up to 1 volt, no radicular muscular contraction at $2-5 \mathrm{~Hz}$ at up to 1 volt, and only local back paresthesia and/or multifidus contraction with stimulation, then the medial branch is anesthetized and one or two 90 second lesions are created. However, once the medial branch has been anesthetized, no additional information regarding sensory or motor stimulation of the medial branch may be obtained. There seem to be some limitations using this methodology.

The objective of this paper is to discuss the development of a new concept regarding the radiofrequency denervation of the lumbar Z-joint.

\section{Development of a New Model}

The author noted that some of the patients, despite convincing responses to diagnostic blocks, continued to have pain following RF Z-joint neurotomy as described above. As a result, some of the patients were reinvestigated by restimulating the lumbar medial branch without denervating them. The author was intrigued to find that, in many cases the lumbar me- dial branch was easily stimulated at a low threshold and that the patients often had success with repeat lumbar medial branch neurotomy. This seemed contrary to conventional wisdom since a RF "zone of coagulation" reaches steady state in $80 \mathrm{sec}$ onds at 83 degrees Celsius in egg yolk (40). One would therefore expect that a properly placed RF probe should ablate the medial branch with a single or double lesion and substantially increase the sensory threshold. This led the author to consider the rationale of the currently recommended RF Z-joint neurotomy technique.

As mentioned above, the concept of evaluating the multifidus twitch seem to be inherently flawed since the goal of the neurotomy is to ablate the sensory fibers and not the motor fibers. In addition, after the multifidus twitch is obtained and the lumbar medial branch anesthetized, no further electrical data may be obtained. This led the author to consider certain concepts of RF "cool lesioning."

When performing a "cool lesion" of the Gasserian ganglion, it is standard to manipulate the position of the RF probe and stimulate at $50 \mathrm{~Hz}$ in each position until the minimal stimulation threshold is less than 0.5 volts and there is no visible or palpable masseter contraction at $2 \mathrm{~Hz}$ between $0.7-1.0$ volts. Once the probe is considered to be optimally placed, a se-

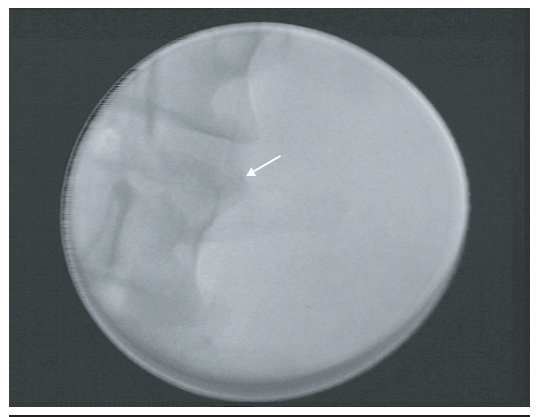

Figure 2. The spot film demonstrates the "groove view." This view is obtained by rotating the image intensifier 20-30 degrees ipsilaterally and 15-25 degrees caudally. The view is referred to as the groove view because it generally demonstrates the groove at the cephlad junction of the transverse process and superior articular process where the medial branch resides. The arrow indicates the position of the groove. 
ries of 60 second lesions are created maintaining the probe temperature at between 60 and 70 degrees Celsius until there has been slight diminution in the corneal reflex and only mild reduction in pin prick sensation in the desired branch of the fifth cranial nerve. The range of temperature for the first lesion is typically between 60 and 65 degrees Celsius and each subsequent lesion is performed at slightly higher temperatures until the desired reduction in sensation is obtained $(41,42)$.

In March 1998, the author decided to utilize a similar model when performing RF Z-joint neurotomy. Since there is no sensory reflex or cutaneous distribution for the medial branch, the sensory threshold was evaluated. To test the theory that the lumbar medial branch is adequately ablated with one or two 90 second lesions, routine anesthetizing of the medial branch during the RF Z-joint ablation would have to be foregone. The author thought that this might prove too painful for the patient to endure but such was not found. Most patients are able to tolerate the RF lesion with routine conscious sedation, local anesthesia of the soft tissues superficial to the transverse process, and gentle, encouraging verbal communication.

When measuring the level of stimulation at which the patient first experiences paresthesia of the un-anesthetized medial branch (minimal sensory threshold), performing a 90 second lesion at 80 degree Celsius, and reassessing the sensory threshold, the author was intrigued by the fact that in the vast majority of cases, no significant change in sensory threshold was found. As a result, the author began creating a series of lesions without moving the probe from its original ideal position and found that as few as 2 and as many as 6 lesions are required to double the sensory threshold in the lumbar spine. Doubling of the sensory threshold was chosen arbitrarily as an acceptable increase in threshold to suggest adequate ablation since the minimal sensory threshold is often as low as 0.2 volts and the interaction of equipment used and response of the slightly sedated patient may not be reliably tracked at a lower increase in threshold.

Following serial RF lesioning and doubling of the sensory threshold at the ideal position, the probe is retracted $5 \mathrm{~mm}$ and the local region is restimulated. The minimal sensory threshold is routinely found to be in the range of $0.8-2.5$ volts, far greater than doubling of the original sensory threshold. Following the described series of lesions, stimulating higher on the superior articular process and more laterally on the transverse process also typically fails to achieve a low sensory stimulation.

\section{Technique}

The patient is positioned prone of the fluoroscopic procedure table and the lumbar and flank region is adequately cleaned with povidone iodine. An IV is started in preparation for conscious sedation. Vital signs are monitored including blood pressure, heart rate, pulse, oxygen saturation, and cardiac rhythm. The fluoroscopic beam is oriented in a 20 30 degrees ipsilateral oblique angle and the image intensifier is rotated $15-20$ degree caudally such that the groove in the cephlad transverse process (groove view) where the medial branch resides is visualized (Fig 2). A 20 G 100mm SMK probe with a $5 \mathrm{~mm}$ exposed bent tip is them placed down to the posterior transverse process parallel to the fluoroscopic beam and periosteum is contacted immediately caudal to the groove in the transverse process. The probe is then manipulated into the groove and the probe is advanced 2-4 $\mathrm{mm}$ distally. The probe is then rotated so that the concavity of the bend "hugs" the transverse process in a medial and 30-45 degree anterior direction thus placing the long axis of the exposed tip immediately adjacent to the medial branch in a curvilinear manner (Fig 3). The medial branch is then stimulated at $50 \mathrm{~Hz}$ carefully determining and recording the minimal sensory threshold which is typically between 0.25 and 0.4 volts. The medial branch is again stimulated at $50 \mathrm{HZ}$ up to $0.8-1.0$ volts to confirm that no radicular stimulation occurs thus implying that the probe is not too near the dorsal root ganglion or spinal nerve. Once it has been confirmed that the probe is optimally positioned as described above, a 90 second lesion at

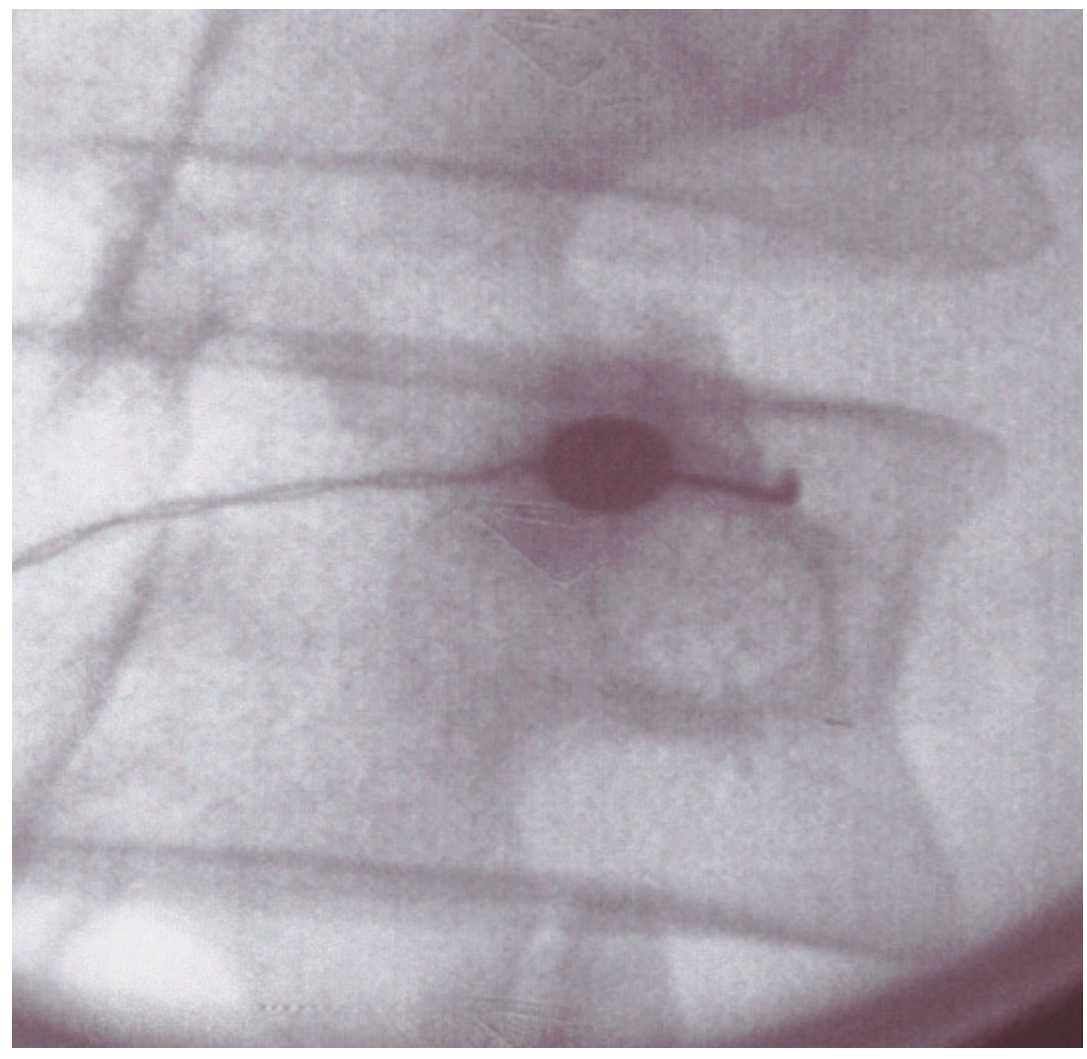

Figure 3. This is a typical location for a curved SMK radiofrequency probe while performing a Z-joint neurotomy. The exposed tip of the radiofrequency probe lies at the cephlad junction of the transverse process and superior articular process. Note that the concavity of the curved tip "hugs" the anterolateral aspect of the superior articular process where the medial branch lies. 
80 degrees Celsius is created. Following the lesion, the minimal sensory threshold is obtained again. If the threshold is not doubled, the process is repeated until the threshold is doubled. Anecdotally, in a large healthy patient doubling of the minimal sensory threshold for the lumbar medial branch often requires 5-6 lesions while a smaller patient or one with diabetes, 2-3 lesions may be adequate. Following this process, the probe is retracted 4 $5 \mathrm{~mm}$ and the minimal sensory threshold is again determined. The vast majority of the time the threshold is between 0.8 and 2.5 volts, substantially more than the typical minimal sensory threshold of 0.25 0.4 volts.

Once the author is satisfied that the medial branch has been adequately ablated, the probe is repositioned near its original groove position and a $0.5 \mathrm{~mL}$ volume of a $1: 1$ solution containing $0.5 \%$ bupivicaine and Celestone is injected to provide additional analgesia and potentially reduce post-procedure pain.

\section{DISCUSSION}

Electromyography of the multifidus muscle provides physiologic information of the motor fibers of the lumbar medial branch. The intent of doing a lumbar medial branch neurotomy is to ablate the sensory fibers of the lumbar medial branch thus rendering the Z-joint asensate or nearly so. Electromyography not only provides delayed information regarding the physiologic status of the lumbar medial branch, it provides physiologic information regarding the status of the motor fibers, not the targeted sensory fibers. In addition, if the patient continues to have pain following the neurotomy and treatment decisions are based upon the results of an abnormal multifidus EMG then the physician may abandon the Zjoint as a potential source of pain. As a result, misguided treatments and potentially more invasive procedures including surgery may be considered.

The described technique focuses on the physiologic status the lumbar medial branch sensory fibers. The author believes that this technique provides the physician with the ability to establish a reproducible, intra-operative, objective physiologic indication that the ability of the lumbar medial branch sensory fibers to conduct electrical stimuli has been dramatically reduced.

It is important to emphasize that the observations made during the 3-1/2 year interval this technique was developed and improved led to this descriptive paper. The original approach and subsequent refinements are reported. Clearly the information contained in this manuscript represent preliminary observations, which need to be subjected to rigorous testing by other interventional pain physicians. Until such is conducted, the routine use of this technique is not advocated.

\section{ConcLusion}

A description of a novel preliminary technique to perform lumbar medial branch neurotomy utilizing the minimal sensory threshold is provided. The technique is not recommended for routine clinical use, until further controlled data are available.

\section{Author Affiliation: \\ Robert E Windsor, MD, \\ Department of Physical Medicine \\ and Rehabilitation, \\ Emory University, \\ President and Director, \\ Georgia Pain Physicians PC, \\ 2550 Windy Hill Road, Suite 215, \\ Marietta, GA 30067 or e-mail: \\ rwindsor@aol.com}

\section{RefERENCES}

1. Marks R. Distribution of pain provoked from lumbar facet joints and related structures during diagnostic spinal infiltration. Pain 1989; 39:37-40.

2. McCall I, Park W, O’Brien J. Induced pain referral from posterior elements in normal subjects. Spine 1979; 5:441-446.

3. McCulloch JA. Percutaneous radio-frequency lumbar rhizolysis (rhizotomy). Appl Neurophysiol 1976/1977; 39:87-96.

4. Mooney V, Robertson J. The facet syndrome. Clin Orthop 1976; 115:149-156.

5. Indahl A, Kaigle AM, Reikeras 0 et al. Interaction between the porcine lumbar intervertebral disc, zygapophysial joints, and paraspinal muscles. Spine 1997; 22:28342840.

6. Carrera GF. Lumbar facet joint injection in low back pain and sciatica. Preliminary results. Radiology 1980; 137:665-667.

7. Fairbank JCT, Park WM, McCall IW et al. Apophyseal injection of local anesthetic as a diagnostic aid in primary low back pain syndromes. Spine 1981; 6:598-605.

8. Schwarzer AC, Aprill CN, Derby $R$ et al. Clinical features of patients with pain stemming from the lumbar zygapophysial joints: Is the lumbar facet syndrome a clinical entity? Spine 1994; 19:1132-1137.
9. Schwarzer AC, Wang S, Bogduk $\mathrm{N}$ et al. The prevalence and clinical features of lumbar zygapophysial joint pain: a study in an Australian population with chronic low back pain. Ann Rheum Dis 1995; 54: 100-106.

10. Manchikanti L, Singh V, Pampati VS et al. Evaluation of the relative contributions of various structures in chronic low back pain. Pain Physician 2001; 4:308-316.

11. Manchikanti L, Pampati VS, Fellows B et al. The diagnostic validity and therapeutic value of medial branch blocks with or without adjuvants. Cur Rev Pain 2000; 4: 337-344.

12. Manchikanti L, Pampati VS, Fellows B et al. The inability of the clinical picture to characterize pain from facet joints. Pain Physician 2000; 3:158-166.

13. Bogduk N. International Spinal Injection Society guidelines for the performance of spinal injection procedures. Part 1: Zygapophysial joint blocks. Clin J Pain 1997; 13: $285-302$

14. Jackson RP, Jacobs RR, Montesano PX. Facet joint injection in low-back pain. A prospective statistical study. Spine 1988;13:966-971.

15. Jackson RP. The facet syndrome. Myth or reality? Clin Orthop 1992; 279:110-121.

16. Schwarzer AC, Aprill CN, Derby $\mathrm{R}$ et al. The false-positive response rate of uncontrolled diagnostic blocks of the lumbar zygapophysial joints. Pain 1994; 58: 195-200.

17. Schwarzer A, Derby R, Aprill C et al. Pain from the lumbar zygapophysial joints: a test of two models. J Spinal Disord 1994; 4: 331-336.

18. Schwarzer AC, Wang S, O’Driscoll D, Harrington $T$ et al. The ability of computed tomography to identify a painful zygapophysial joint in patients with chronic low back pain. Spine 1995; 20:907-912.

19. Revel M, Chevalier X, Dougados M et al. Facet joint block for low back pain: identifying predictors of a good response. Arch Phys Med Rehabil 1992; 73:824-828.

20. Revel M, Poiraudeau S, Auleley G et al. Capacity of the clinical picture to characterize low back pain relieved by facet joint anesthesia. Proposed criteria to identify patients with painful facet joints. Spine 1998; 23:1972-1976.

21. Destouet JM, Gilula LA, Murphy WA et al. Lumbar facet joint injection: indication, technique, clinical correlation and preliminary results. Radiology 1982; 145:321325.

22. Dory MA. Arthrography of the lumbar facet joints. Radiology 1981; 140:23-27.

23. Auteroche P. Innervation of the zygapophysial joints of the lumbar spine. Anat Clin 1983; 5:17-28.

24. Emminger E. Les articulations interapophysaires et leurs structures meniscoides vue sous l'angle de la pathologie. Annales de Medecine Physique 1972; 15:219238. 
25. Lazorthes G, Juskiewenski S. Etude comparative des branches posterieures des nerfs dorsaux et lombaires et de leurs rapports avec les articulations interapophysiares vertebrales. Bulletin de l'Association des Anatomistes, 49e Reunion 1964; 10251033.

26. Paris SV. Anatomy as related to function and pain. Orthop Clin North Am 1983; 14: 475-489.

27. Dreyfuss P, Schwarzer AC, Lau P et al. The target specificity of lumbar medial branch and $L_{5}$ dorsal ramus blocks. A computed tomography study. Spine 1997; 22:895902.

28. Kaplan M, Dreyfuss P, Halbrook B et al. The ability of lumbar medial branch blocks to anesthetize the zygapophysial joint- a physiologic challenge. Spine 1998; 23: 1847-1852.

29. Bogduk N, Wilson AS, Tynan W. The human lumbar dorsal rami. J. Anat 1982; 134: 383-397.

30. Bradley KC. The anatomy of backache. Aust N Z J Surg 1974; 44:227-232.

31. Lewen T, Moffet B, Viidik A. The morphol- ogy of the lumbar synovial intervertebral joints. Acta Morphol Neerland Scand 1962; 4:299.

32. Pederson HE, Blunck CFJ, Gardner E. The anatomy of lumbosacral posterior ram and meningeal branches of spinal nerves (sinu-vertebral nerves). J Bone Joint Surg (Am) 1956; 38A:377-391.

33. Oudenhoven RC. Paraspinal electro-myography following facet rhizotomy. Spine 1977; 2:299-304.

34. Dreyfuss P, Halbrook B, Pauza K et al. Efficacy and validity of radiofrequency neurotomy for chronic lumbar zygapophysial joint pain. Spine 2000; 25:1270-1277.

35. Barendse G, Spaans F, Stomp-van den Berg $S$ et al. Local denervation of lum bar paraspinal muscles may not be used as a criterion for the effectivity of radiofrequency lesions of the zygapophysial joints. Pain Clinic 2001;13:125-132.

36. Sluijter $M$. The use of radiofrequency lesions for pain relief in failed back patients. Int Disabil Studies 1988;10:1-7.

37. Andersen K, Mosdal C, Vaernet K. Percuta- neous radiofrequency facet denervation in low back and extremity pain. Acta Neurochir 1987;87:48-51.

38. Burton C. Percutaneous radiofrequency facet denervation. Appl Neurophysiol 1976;39:80-86.

39. vanKleef M, Barendse G, Kessels A et al. Randomized trial of radiofrequency lumbar facet denervation for chronic low back pain. Spine 1999;24:1937-1949.

40. Bogduk N, Macintosh J, Marsland A. Technical limitations to the efficacy of radiofrequency neurotomy for spinal pain. I Neurosurg 1987;20:529-525.

41. Kline $M$ (ed). Stereotactic radiofrequency lesions as part of the management of pain. St. Lucey Press, Delray Beach, 1996, pp 59-63.

42. Broggi G, Franzini A, Lasio $G$ et al. Long term results of percutaneous retrogasserian thermorhizotomy for "essential" trigeminal neuralgia: considerations in 1000 consecutive patients. J Neurosurg 1990; 26:783-786. 
